\title{
Editorial for Special Issue "Fluid Inclusion Characteristic of the Gold Deposit and Its Implication for Ore Genesis"
}

\author{
Vsevolod Yu. Prokofiev \\ Institute of Geology of Ore Deposits, Petrography, Mineralogy, and Geochemistry, Russian Academy of Sciences, \\ 119017 Moscow, Russia; vpr@igem.ru
}

Received: 18 February 2020; Accepted: 4 March 2020; Published: 6 March 2020

Fluid inclusions provide valuable information on the composition and physical and chemical parameters of mineral-forming hydrothermal fluids. Different types of gold deposits have distinctive fluid inclusions in the minerals of ore deposits ([1]). Numerous studies have shown that the minerals of epithermal gold deposits contain low-density water vapor, which indicates fluid boiling at temperatures of $400-100{ }^{\circ} \mathrm{C}$ under low pressures. Fluids of gold-porphyry deposits have a wide range of salinity and the presence of low-density gas phases (heterogeneous state of the fluid), which were entrapped at high-temperature (up to $700-800^{\circ} \mathrm{C}$ ) and high pressures (up to $700 \mathrm{bar}$ ). The fluids of vein deposits hosted by terrigenous strata and orogenic gold deposits consist of two phases-a dense gas phase (carbon dioxide with generally lesser amounts of nitrogen and methane) and a water-salt solution, which often contains dissolved carbon dioxide. The fluids of the deposits associated with granitoid intrusions are similar to the fluids of orogenic gold deposits, but often differ by higher concentrations of salts.

In this Special Issue, fluid inclusions research methods are presented for different types of $\mathrm{Au}$ and Ag deposits. The majority of papers are focused on Au-Cu porphyry deposits, since this type of deposit is economically productive.

The first paper [2] deals with the Kışladağ porphyry gold deposit in western Turkey. The deposit is hosted by a mid-Miocene monzonite magmatic complex consisting of three intrusions. The gold mineralization is hosted in all of them, but intrusion 1 is the best mineralized body followed by intrusion 2. Fluid inclusion studies show that the gold-hosting early phase quartz 1 of veins 1 and 2 crystallized at high temperatures (Th between 424 and $594{ }^{\circ} \mathrm{C}$ ). The coexisting and similar ranges of Th values of vapor-rich (low salinity, from $1 \%$ to $7 \% \mathrm{NaCl}$ equivalent) and halite-bearing (high salinity: $>30 \% \mathrm{NaCl}$ ) fluid inclusions in early quartz indicate that the magmatic fluid separated into vapor and high-salinity liquid along an isotherm. Fluid inclusions in quartz 2 were trapped at lower temperatures and had lower salinities. The low salinity and low formation temperature of quartz 4 may be explained by the mixing of meteoric water with the hydrothermal system, or by later-stage epithermal overprinting. The separation of the magmatic fluid into vapor and aqueous saline pairs in the quartz 1 of the vein $1 \mathrm{CO}_{2}$-poor fluids indicates that the Kışladağ porphyry gold deposit was produced at a shallow depth.

The next paper [3] deals with to the Jinchang gold-rich gold-copper porphyry deposit in Eastern Heilongjiang Province, Northeastern China. The orebody comprises primarily hydrothermal breccias, quartz veins, and disseminated ores in granite, diorite, and granodiorite. Fluid inclusions at this deposit are liquid-rich aqueous, vapor-rich aqueous, and daughter-mineral-bearing types. Microthermometric data indicate that the homogenization temperatures and salinities of the ore-forming fluids decreased with time. Oxygen and hydrogen isotope data suggest that the ore-forming fluids were derived from magmatic fluids during the early mineralizing process and subsequently incorporated meteoric water. The sulfide minerals provide evidence that the sulfur is of magmatic origin. 
The Tocantinzinho gold deposit [4], located in the Tapajós Mineral Province, Amazonia, Brazil, is considered to be the largest gold deposit in the region. Gold is mainly associated with phyllic alteration. The primary fluid inclusions trapped during the mineralization stages are $\mathrm{H}_{2} \mathrm{O}-\mathrm{NaCl}$, unsaturated, and homogenize either to the vapor or to the liquid with $T$ h of $300-430{ }^{\circ} \mathrm{C}$, their salinity is $2-16 \mathrm{wt} \%$ $\mathrm{NaCl}$ equiv. and the density is 0.43 to $0.94 \mathrm{~g} / \mathrm{cm}^{3}$. Although Tocantinzinho shows similarities with magmatic-hydrothermal oxidized calc-alkaline granite-related gold deposits classified as porphyry gold deposits, it has been classified with porphyry-style gold deposits, because it lacks some features of Phanerozoic porphyry-type deposits.

Review paper [5] focuses on ore-forming fluids of orogenic gold deposits. The paper reviews data from numerous publications presenting the physicochemical parameters and chemical composition of ore-forming fluids at orogenic gold deposits formed during various geological epochs. The paper analyzes how the principal parameters of mineralizing fluids are distributed depending on the age of the mineralization. Some parameters of the fluids (their salinity and pressure) at orogenic gold deposits are demonstrated to systematically vary from older to younger deposits. The statistically significant differences detected between some parameters of mineralizing fluids at orogenic gold deposits are principally new information. The parameters at which mineralization of various age was formed are demonstrated to pertain to different depth levels of similar mineralization-forming systems. The fluid parameters of the most ancient deposits (which are mostly deeply eroded) correspond to the deepest levels of orogenic fluid systems. Hence, the differences in the salinity and pressure of the mineralizing fluids at orogenic deposits of different age reflect the vertical zoning of the mineralizing fluid systems.

The Detour Lake orogenic gold deposit in Canada [6] is mapped as to a faulted contact between mafic volcanic and siliciclastic to volcaniclastic rocks. This deposit differs from other greenschist facies orogenic Au deposits in the Abitibi region as the Au is hosted in amphibolite facies host rocks. As a result, typical indicator minerals of the mineralization such as secondary biotite cannot be used to locate mineralized zones because this would require distinguishing the products of hydrothermal processes from the metamorphic and magmatic ones. Herein, geochemical and ${ }^{40} \mathrm{Ar} /{ }^{39} \mathrm{Ar}$ geochronological data are presented for biotite from mineralized and barren (distal) magmatic rocks to characterize the potential geochemical and geochronological variations between biotite types. The newly reported results suggest chemical variability of the biotite was caused by a post-mineralization hydrothermal event, and hence, the biotite should be used cautiously as a vector for gold mineralization in amphibolite facies terranes.

The large gold-telluride deposit related to the deposit in Svetlinsk, Russia [7] is thought to be of an unusual type for the Urals, and the origin of this deposit is disputable. A feature distinguishing this deposit from the others is the abundance of various tellurides, such as tellurides of $\mathrm{Fe}, \mathrm{Ni}, \mathrm{Pb}, \mathrm{Sb}, \mathrm{Bi}$, $\mathrm{Ag}$, and Au. Newly acquired microthermometric, Raman spectroscopic, LA-ICP-MS, and crush-leach analysis data (gas and ion chromatography, ICP-MS) of fluid inclusions and data on the oxygen isotope composition of the quartz were used to calculate the P-T-X parameters of the ore-forming processes and estimate the fluid sources at the deposit. Mineralization was formed within wide temperature and pressure $\left(200-400{ }^{\circ} \mathrm{C}, 1-4 \mathrm{kbar}\right)$ ranges by contrasting fluids from multiple sources. During the early stages, the magmatic fluid evolved during its ascent and phase separation, and fluids derived from the host rock by their decarbonation and dehydration were involved in the hydrothermal system. In addition, mantle-derived fluid might be involved in the ore-forming process during gold-telluride precipitation. Heated meteoric waters during the late stages were likely involved. The early fluids were rich in $\mathrm{H}_{2} \mathrm{~S}, \mathrm{~S}_{0}$, and $\mathrm{CH}_{4}$, while the Au-Te mineralization was formed from $\mathrm{N}_{2}$-rich fluid.

The intrusion to which the Shanmen silver deposit [8] is related occurs in the southeastern part of the Siping area, Jilin Province. This deposit is one of the large Ag deposits in northeastern China. In almost all of the Ag orebodies, the Ag-bearing quartz-sulfide veins are strictly controlled by NE-trending faults or brittle fractures and are hosted in the Yanshanian monzonite and quartz diorite. Data acquired on the fluid inclusions entrapped during different stages indicate that the early stage (Stage I) mainly contains three types of fluid inclusions: liquid-rich two-phase (L-type), vapor-rich 
two-phase (V-type), and $\mathrm{CO}_{2}$ aqueous multi-phase (C-type). The fluid belongs to a medium-high temperature and medium-to-low salinity $\mathrm{H}_{2} \mathrm{O}-\mathrm{NaCl}-\mathrm{CO}_{2}$ system and has boiling characteristics. The middle stage (Stage II) is characterized mainly by liquid-rich two-phase (L-type) and vapor-rich two-phase (V-type) inclusions, in which the mixing of fluids of different nature leads to the escape of $\mathrm{CO}_{2}$. Only liquid-rich two-phase (L-type) inclusions are distinguished in the late stage (Stage III). The fluids of the two later stages belong to a medium-low-temperature and low-salinity $\mathrm{H}_{2} \mathrm{O}-\mathrm{NaCl}$ system. The gradually decreasing homogenization temperatures and salinities and the decrease in the $\mathrm{CO}_{2}$ content indicate that the release of $\mathrm{CO}_{2}$ in a low-temperature environment was an important cause for the precipitation of Ag-bearing minerals. Isotopic data indicates that the initial ore-forming fluid was derived mainly from magma and that the input of meteoric water gradually increased during the mineralization process, and the mixing of fluids of different nature was the main mechanism causing precipitation.

The paper by Yang et al. [9] is devoted to an improvement in the methodology of studying fluid inclusions. In this paper, a new calculation method is proposed to accurately solve the $\mathrm{V}$-x parameters of $\mathrm{H}_{2} \mathrm{O}-\mathrm{NaCl}-\mathrm{CO}_{2}$ fluid inclusions with complete homogenization temperature lower than $300{ }^{\circ} \mathrm{C}$. The algorithm first determines the salinity of inclusions with respect to the melting temperature of $\mathrm{CO}_{2}$ clathrate and the partial homogenization temperature of the $\mathrm{CO}_{2}$ phase and then determines the internal pressure of inclusions when $\mathrm{CO}_{2}$ clathrate is completely melted. The $\mathrm{V}$-x parameters of the inclusions are then iteratively solved. The new algorithm does not require a visual estimation of the volume fraction of the $\mathrm{CO}_{2}$ phase as an input parameter. It is possible to avoid the significant error brought about by the method traditionally applied to calculate the V-x parameters of inclusions with the visual estimation of the $\mathrm{CO}_{2}$ phase volume fraction. A computer program is developed on the basis of the new method and is applied in the analysis of fluid inclusions in medium- and low-temperature hydrothermal gold ore.

Generally, the papers published in the Special Issue give an overview of the current level of studying fluid inclusions to better understand the genesis of gold deposits. We hope this special issue will serve as a resource and inspiration for future studies in this vibrant and topical field of research.

Funding: This research received no external funding.

Conflicts of Interest: The author declares no conflict of interest.

\section{References}

1. Bodnar, R.J.; Lecumberri-Sanchez, P.; Moncada, D.; Steele-Maclnnes, P. Fluid Inclusions in Hydrothermal Ore Deposits. In Treatise on Geochemistry, 2nd ed.; Elsevier: Amsterdam, The Netherlands, 2014; pp. 119-142.

2. Hanilçi, N.; Bozkaya, G.; Banks, D.A.; Bozkaya, O.; Prokofiev, V.; Öztaş, Y. Fluid Inclusion Characteristics of the Kışladağ Porphyry Au Deposit, Western Turkey. Minerals 2020, 10, 64. [CrossRef]

3. Li, S.; Zhang, X.; Gao, L. Ore Genesis at the Jinchang Gold-Copper Deposit in Heilongjiang Province, Northeastern China: Evidence from Geology, Fluid Inclusions, and H-O-S Isotopes. Minerals 2019, 9, 99. [CrossRef]

4. Lopes, A.A.C.; Moura, M.A. The Tocantinzinho Paleoproterozoic Porphyry-Style Gold Deposit, Tapajós Mineral Province (Brazil): Geology, Petrology and Fluid Inclusion Evidence for Ore-Forming Processes. Minerals 2019, 9, 29. [CrossRef]

5. Prokofiev, V.Y.; Naumov, V.B. Physicochemical Parameters and Geochemical Features of Ore-Forming Fluids for Orogenic Gold Deposits Throughout Geological Time. Minerals 2020, 10, 50. [CrossRef]

6. Dubosq, R.; Schneider, D.A.; Camacho, A.; Lawley, C.J.M. Geochemical and Geochronological Discrimination of Biotite Types at the Detour Lake Gold Deposit, Canada. Minerals 2019, 9, 596. [CrossRef]

7. Vikent'eva, O.; Prokofiev, V.; Borovikov, A.; Kryazhev, S.; Groznova, E.; Pritchin, M.; Vikentyev, I.; Bortnikov, N. Contrasting Fluids in the Svetlinsk Gold-Telluride Hydrothermal System, South Urals. Minerals 2020, 10, 37. [CrossRef] 
8. Sun, X.; Ren, Y.; Cao, P.; Hao, Y.; Gao, Y. Ore Genesis of Shanmen Ag Deposit in Siping Area of Southern Jilin Province, NE China: Constraints from Fluid Inclusions and H-O, S, Pb Isotopes. Minerals 2019, 9, 586. [CrossRef]

9. Yang, S.; Sun, R.; Liu, X.; Liu, Z.; Wen, J. Accurate Calculation Procedure for V-x Parameters of Hydrothermal Gold Ore Fluid Inclusions. Minerals 2019, 9, 673. [CrossRef] 